Revista de Iniciação Científica em Odontologia. 2018;16(3):145-150

ISSN 1677-3527 - DOI: 10.4034/RevICO.2018.16.3.15

Relato de Caso

\title{
Terceiro molar incluso diagnosticado previamente à cirurgia ortognática: Relato de caso
}

Third molar even diagnosed before orthognathic surgery: Case report

\author{
Larissa Suelen da Silva Lins ${ }^{1}$; Fernanda Barros da Silva1; Murilo Quintão dos Santos²; Anderson \\ Maikon de Souza Santos²; Tiburtino José de Lima Neto²; Marcos Antônio Farias de Paiva².
}

\begin{abstract}
${ }^{1}$ Graduanda em Odontologia pela Universidade Federal da Paraíba, João Pessoa, Paraíba, Brasil. ${ }^{2}$ Residente em CTBMF no hospital universitário Lauro Wanderley, João Pessoa, Paraíba, Brasil. ${ }^{3}$ Professor do curso de Odontologia, Universidade Federal da Paraíba, João Pessoa, Paraíba, Brasil.
\end{abstract}

Autor e endereço para correspondência:

Larissa Suelen da Silva Lins, Rua Professora Luiza Fernandes Vieira, 511, Cristo Redentor, João Pessoa, Paraíba. CEP: 58071-280. E-mail: larissass|@hotmail.com

\begin{abstract}
Resumo
Introdução: Deformidades dento faciais são má oclusões severas, as quais não podem ser corrigidas somente por tratamento ortodôntico convencional sendo necessária intervenção cirúrgica por meio da cirurgia ortognática cujo objetivo principal é reestabelecer a relação funcional entre os ossos gnáticos, onde a ortodontia é um coadjuvante importante para o condicionamento pré e pós operatório. Uma anamese bem feita associada a exames de imagem são imprescindíveis no preparatório para a cirurgia. Relato de Caso: Neste artigo objetivou-se relatar o diagnóstico de um elemento dental incluso em região posterior de maxila direita, verificado durante 0 preparo ortodôntico para realização da cirurgia, e a conduta adotada.
\end{abstract}

Descritores: Dente não erupcionado, Cirurgia ortognática, Má oclusão de Angle classe III. 


\begin{abstract}
Introduction: Tooth deformities are severe malocclusions, which can not be corrected only by conventional orthodontic treatment where surgical intervention is necessary through orthognathic surgery, whose main objective is to reestablish the functional relationship between the gnathic bones, where orthodontics is an important adjuvant for pre and post operative conditioning. A well-made anamnesis associated with imaging examinations is essential in the preparation for surgery. Case report: This article aimed to report the diagnosis of a dental element included in the posterior region of the right maxilla, verified during orthodontic preparation for surgery, and the adopted procedure.
\end{abstract}

Keywords: Tooth Unerupted, Orthognathic Surgery, Malocclusion Angle Class III.

\title{
Introdução
}

O perfil dentário de pacientes que necessitam de correção ortodôntica ou orto-cirúrgica para deformidades dentofaciais geralmente são baseadas na classificação de Angle, e em sua maioria estão os pacientes com má oclusão esquelética de classe III'1.

As deformidades dentofaciais são desvios das proporções faciais normais e das posições dentárias o que desencadeiam prejuízos estéticos e funcionais aos pacientes, como dificuldade mastigatória, de deglutição, de comunicação, o não selamento labial, e até na função respiratória.

As cirurgias ortognáticas têm por objetivo realinhar os ossos gnáticos até que mantenham uma relação funcional, ideal ou aceitável, em pacientes que possuam deformidades dento-faciais. Para tanto é necessário que o paciente seja submetido a um tratamento ortodôntico antes e após a cirurgia².

\section{Relato de Caso}

Paciente, sexo masculino, 27 anos, procurou o serviço de cirurgia e traumatologia bucomaxilofacial do hospital universitário Lauro Wanderley, encaminhado pela ortodontista, para 
avaliação, planejamento e conduta de cirurgia ortognática. Ao exame físico foi observado que o paciente possuía deformidade dento facial, classe III de Angle, com excesso antero posterior de mandíbula associada a deficiência transversa de maxila, com mordida cruzada porterior e anterior, que o enquadravam em necessidade de cirurgia ortognática (Figuras 1 e 2). No plano de tratamento cirúrgico foi proposto realizar uma expansão maxilar para aumentar a dimensão lateral, nivelamento e alinhamento, seguidos de avanço da maxila e retrusão mandibular.

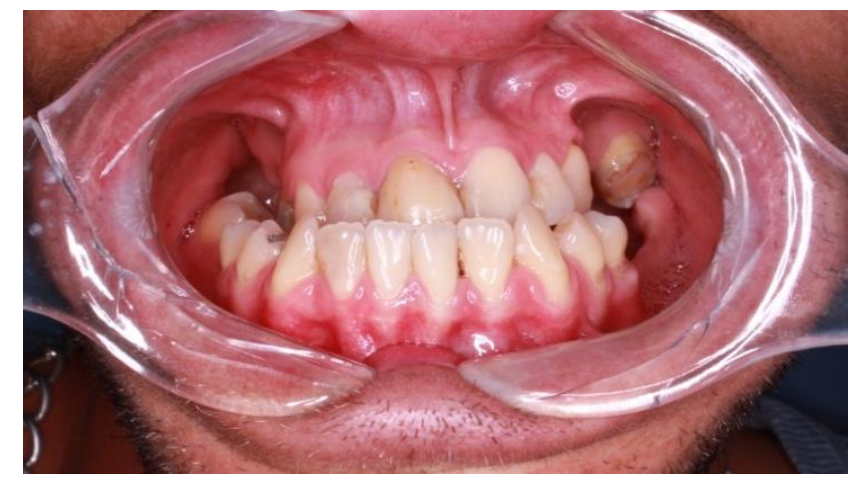

Figura 1. Aspecto clínico inicial.

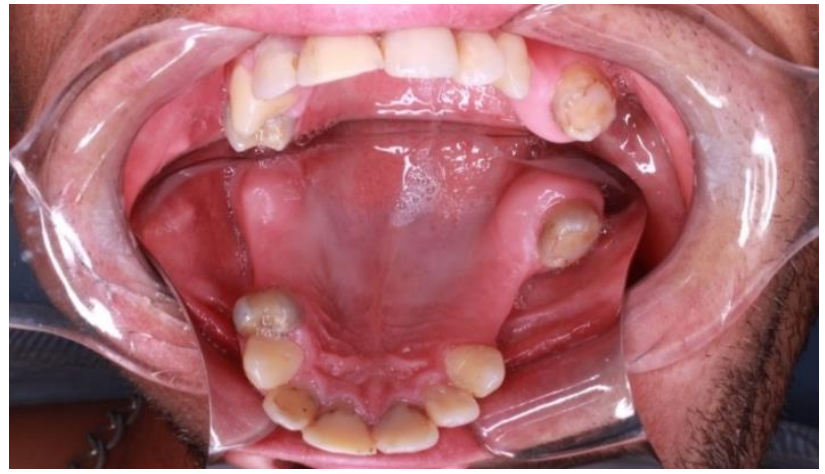

Figura 2. Aspecto clínico inicial.

Foram solicitadas radiografia panorâmica e teleradiografia de perfil (Figuras 3 e 4), onde foi evidenciado a presença de um elemento dental incluso em região posterior de maxila direita, sugerindo um terceiro molar incluso. O dente poderia ser removido durante a cirurgia ortognática, entretanto, optou-se por realizar a remoção do elemento dental antes do procedimento, utilizando anestesia local, e por acesso intraoral, com o objetivo de facilitar o transoperatório, o qual já apresentaria uma complexidade maior devido à estrutura dos maxilares (Figura 5). 
Revista de Iniciação Científica em Odontologia 2018;16(3):145-150.

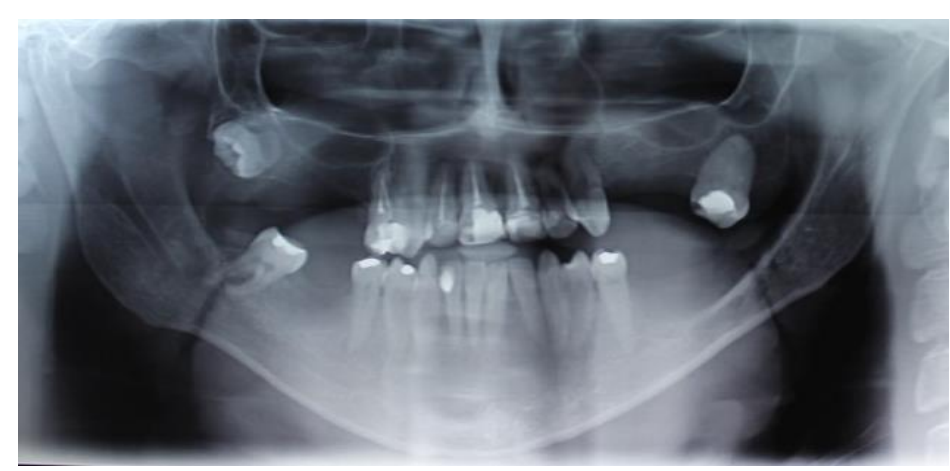

Figura 3. Radiografia Panorâmica.

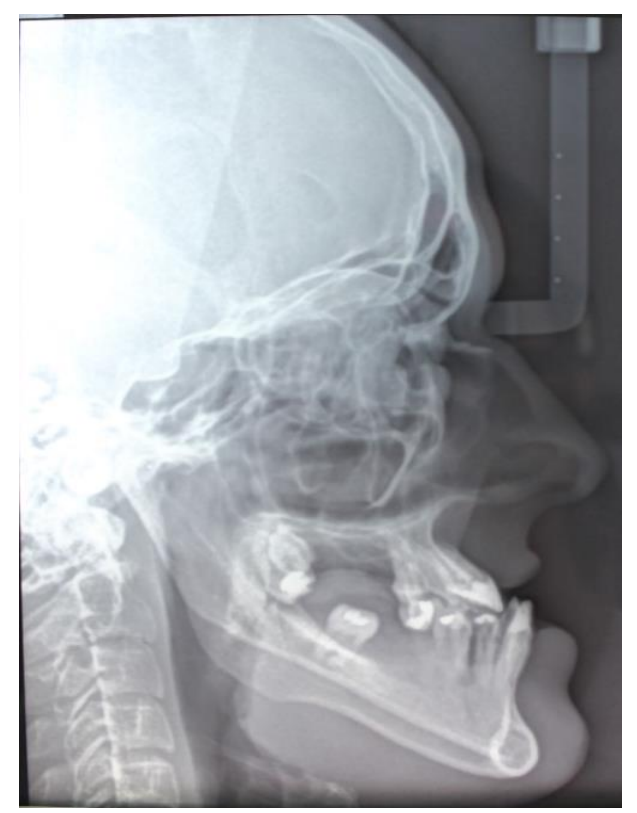

Figura 4. Telerradiografia de Perfil.

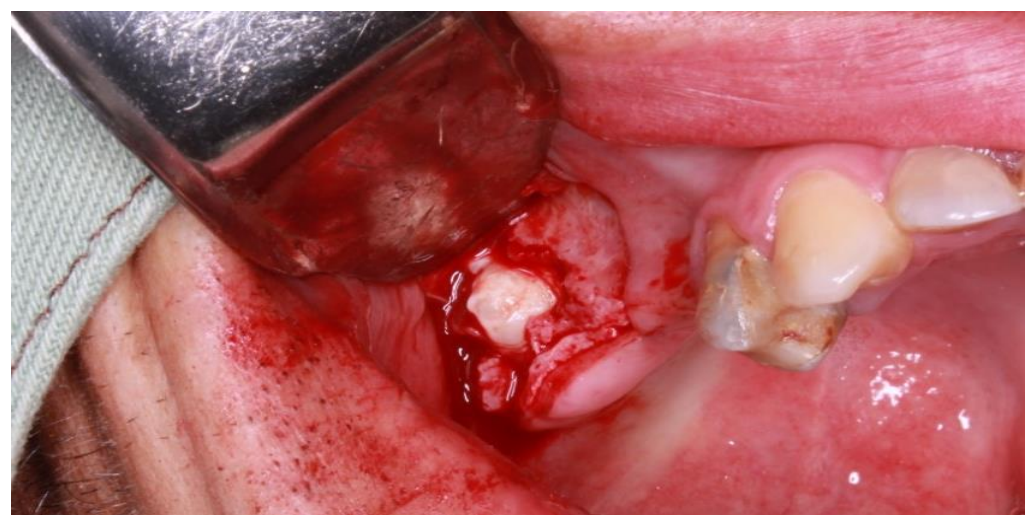

Figura 5. Transoperatório. 
Após remoção do elemento dental, o paciente foi encaminhado para continuar o tratamento ortodôntico prévio a cirurgia, para alinhamento e nivelamento dos arcos.

\section{Discussão}

O preparatório para a cirurgia ortognática começa na fase de pré-operatório onde o paciente é diagnosticado, tanto através do exame físico minucioso, como por meio de radiografias, modelos de estudo, análises cefalométricas. Em seguida é feito o planejamento ortocirúrgico. Inicialmente são eliminadas as compensações dentárias na fase de nivelamento e alinhamento ortodôntico ${ }^{3}$, posteriormente é feita o fechamento dos espaços interdentais, e estabilização dos $\operatorname{arcos}^{4}$. É necessário solicitação de nova documentação de imagem, e modelos de estudo ${ }^{5}$, para só então passar para a fase cirúrgica.

Os dentes inclusos são caracterizados por não erupcionar na cavidade bucal e ficarem retidos dentro dos tecidos, isso se dá na maioria das vezes por falta de espaço na arcada, mas também por fatores hereditários, alterações patológicas, fatores locais, entre outros. Existem algumas controvérsias quanto a necessidade de remover os dentes inclusos, entretanto, sabe-se que todo elemento dental incluso apresenta riscos de provocar alterações patológicas, pericoronarites, apinhamento de elementos dentais vizinhos entre outros, portanto, as exodontias preventivas de dentes inclusos são cada vez mais frequentemente utilizadas ${ }^{6}$.

O desconforto pós-operatório é mencionado por alguns autores como argumento para não remover o dente incluso, entretanto, este é considerado para a maioria dos autores, como de menor valor quando comparado aos benefícios e qualidade de vida a longo prazo o que não justificaria a não realização da exodontia ${ }^{7}$.

\section{Conclusão}

A fase pré-operatória é imprescindível para o planejamento orto-cirúrgico integrado, bem como para o diagnóstico de lesões, elementos dentários, entre outras estruturas que possam interferir no sucesso da cirurgia ortognática.

É importante realizar a remoção de elementos dentários inclusos de maneira profilática, e principalmente previamente a cirurgias ortognáticas, tendo em vista que em casos mais complexos, a remoção do elemento no transoperatório pode vir a dificultar ainda mais o procedimento, sendo preferível nesses casos realizar a exodontia previamente à cirurgia. 


\section{Referências}

1. Kulczynsk $F$, et al. Postural assessment in class III patients before and after orthognathic surgery. J Oral Maxillofac Surg. 2018; 76(2): 426-435.

2. Eslamipour $\mathrm{F}$, et al. A Retrospective Analysis of Dentofacial Deformities and Orthognathic Surgeries. Ann Maxillofac Surg. 2017; 7(1): 73-77.

3. Manganello LC, Silveira ME. Cirurgia Ortognática e Ortodontia 2ed. São Paulo: Santos, 2010.

4. Cardoso MA, Capelozza Filho L, Guedes FP, Cappellozza JÁ, Nary Filho H. Tratamento ortodôntico cirúrgico de Padrão III: relato de caso clínico. Orthod. sci. pract. 2011 ; 3(13): 425446.

5. Cardoso RM, Cardoso RM. Cirurgia Ortognática: Orientações Ortodônticas. Int J Dent Recife. 2009; 8(2): 94-97.

6. Ventä I, Ylipaavalniemi P, Turtola L. Longterm evaluation of estimates of need for third molar removal. J Oral Maxillofac Surg, 2001; 58(3):288-291.

7. McGrath C, Comfort MB, Lo EC, Luo Y. Can Third Molar Surgery Improve Quality of Life? A 6Month Cohort Study, J Oral Maxillofac Surg. 2003; 61(7):759-763. 